\title{
PCCP
}

Cite this: Phys. Chem. Chem. Phys., 2011, 13, 7903-7909

\section{Cyclodextrin-based systems for photoinduced hydrogen evolution}

\author{
Nikos Mourtzis, ${ }^{a}$ Pablo Contreras Carballada, ${ }^{b}$ Marco Felici, ${ }^{a}$ \\ Roeland J. M. Nolte, ${ }^{a}$ René M. Williams, ${ }^{* b}$ Luisa de Cola ${ }^{c}$ and \\ Martin C. Feiters $* a$
}

\author{
Received 13th December 2010, Accepted 1st March 2011 \\ DOI: $10.1039 / \mathrm{c0cp02867c}$
}

Light-driven catalytic three component systems for the reduction of protons, consisting of a cyclodextrin-appended iridium complex as photosensitizer, a viologen-based electron relay, and cyclodextrin-modified platinum nanoparticles as the catalyst, were found to be capable of producing molecular hydrogen effectively in water, using a sacrificial electron donor. The modular approach introduced in this study allows the generation of several functional photo-active systems by self-assembly from a limited number of building blocks. We established that systems with polypyridine iridium complexes of general formula $\left[\operatorname{Ir}(\mathrm{ppy})_{2}(\mathrm{pytl}-\mathrm{R})\right] \mathrm{Cl}$ (ppy, 2-phenylpyridine; pytl, 2-(1-substituted-1H-1,2,3-triazol-4-yl)pyridine) as photosensitizers are active in the production of $\mathrm{H}_{2}$, with yields that under our experimental conditions are 20-35 times higher than those of the classical system with $\left[\mathrm{Ru}(\mathrm{bpy})_{3}\right] \mathrm{Cl}_{2}$ (bpy, 2,2'-bipyridine), methyl viologen, and $\mathrm{Pt}$. By investigating different photocatalytic systems, it was found that the amount of hydrogen produced was directly proportional to the emission quantum yield of the photosensitizer.

\section{Introduction}

The large-scale production of clean energy is one of the major challenges society is currently facing. The exhaustion of fossil fuels and the tangible influence of the greenhouse effect on the environment increase the need to switch from carbon-based fuels (coal, gas, and oil) to renewable energy sources with less or no impact on the environment (solar, wind, wave power, biomass, and wood). ${ }^{1}$ Molecular hydrogen is commonly recognized as a key sustainable fuel for the future because it has a high energy content and its combustion produces only water. $^{2}$ It does not occur in large amounts on earth, but has to be produced from substances containing hydrogen atoms such as water or fossil fuels; it is therefore to be considered as an energy carrier rather than an energy source, and it becomes a sustainable alternative to classical fuels only if it is produced in a clean fashion. Globally, the industry already produces and uses hydrogen on a massive scale. However, its current production is largely based on fossil fuels which is relatively

${ }^{a}$ Organic Chemistry, Institute for Molecules and Materials, Faculty of Science, Radboud University Nijmegen,

Heijendaalseweg 135, 6525 AJ Nijmegen, The Netherlands.

E-mail:m.feiters@science.ru.nl; Fax: + 3124 3652929;

Tel: + 31243652016

${ }^{b}$ Van't Hoff Institute for Molecular Sciences, Molecular Photonics Group, Science Park 904, 1098 XH Amsterdam, The Netherlands.

E-mail:R.M.williams@uva.nl; Fax: +31(0)20 525 6456;

Tel: + $31(0) 205255477$

${ }^{c}$ Physikalisches Institut, Westfälische Wilhelms-Universität Münster,

Wilhelm-Klemm-Str. 10, 48149 Münster, Germany energy inefficient, and leads to the emission of a significant amount of greenhouse gases. ${ }^{3}$ The production of hydrogen using solar energy represents an ideal example of production of sustainable energy. 4

The development of a future based on hydrogen requires several technical aspects to be considered. Governments and industries, particularly in the United States, Japan, and Europe, have been investing heavily in research and development to overcome the technical barriers for the use of hydrogen, which include $^{4}$ (i) sustainable production, (ii) purification, ${ }^{5}$ (iii) storage/ distribution, ${ }^{6}$ and (iv) utilization. ${ }^{7}$

More than thirty years ago, Lehn and Grätzel showed independently ${ }^{8-10}$ that the now classical three component heterogeneous photocatalytic system, consisting of a photosensitizer, an electron carrier, and a catalyst for hydrogen evolution, can be used for the generation of molecular hydrogen from water and a sacrificial electron donor. Several studies have been reported on systems containing different photosensitizers, sacrificial electron donors, variously substituted viologens and a variety of catalysts such as semiconductor metal oxides and noble metal particles. ${ }^{2}$ The catalysts initially used by Grätzel and Lehn were semiconductors, which were effective only under ultraviolet (UV) light because of their wide band gap. The development of new photocatalysts that are able to produce $\mathrm{H}_{2}$ from water to make systems active over the whole visible spectrum has therefore attracted much attention. ${ }^{11-17}$ Metal complexes have long been explored as photosensitizers for the evolution of hydrogen in combination with different catalysts. ${ }^{18-25}$ There is a wide range of molecules 
that can act as photosensitizers such as organic dyes, inorganic systems as well as organometallic complexes. ${ }^{26-28}$ In a typical catalytic cycle, the photosensitizer, which has been oxidized by the catalyst, needs to be regenerated by an electron source (sacrificial donor) which is consumed during the hydrogen production. In combination with a colloidal $\mathrm{Pt}$ catalyst, methyl viologen ([Me-V-Me $] \mathrm{Cl}_{2}$ ) is frequently employed as an electron carrier between the sensitizer and the catalyst. The important steps in these systems are the photo-induced electron transfer from a photo-excited sensitizer to Me-V-Me and the subsequent electron-transport to a colloidal Pt catalyst by the reduced methyl viologen $\left([\mathbf{M e}-\mathbf{V}-\mathbf{M e}]^{{ }^{+}}{ }^{+}\right.$).

Scheme 1 shows the typical assembly of photocatalytic systems with an organometallic complex as sensitizing dye. These complexes are photo- and electro-active molecules and typical examples are $\mathrm{Ru}$ and Ir polypyridine complexes. ${ }^{29-33}$ These compounds are capable of absorbing light from the UV-visible part of the electromagnetic spectrum creating a long-lived excited state that is able to transfer one electron to the electron relay (viologen) in a reversible redox process. The reduced viologen is then a strong reductant which is capable of transferring electrons to the platinum particle surface where they combine with $\mathrm{H}^{+}$to form molecular hydrogen. In these systems, light acts as a pump forcing the electrons in the direction of the catalytic center. Probably, the biggest disadvantages of this kind of catalytic cycles are that they depend on the efficiency of collisions between the redox partners, which is limited, and that deactivation processes can occur such as the dimerization of the reduced viologen into electro-inactive species as well as its irreversible hydrogenation. ${ }^{34}$

In our approach we investigate an analogously constructed three component system containing (i) as sensitizers the complexes $\left[\mathrm{Ru}(\text { bpy })_{2}(\text { pytl- } \beta C D)\right]^{2+}$ or $\left[\operatorname{Ir}(\text { ppy })_{2}(\text { pytl- } \beta C D)\right]^{+}$ on which we reported previously, ${ }^{35}$ (ii) as electron relay a (substituted) viologen, and (iii) a functionalized platinum catalyst (Scheme 2). The photoinduced electron-transfer step may be improved by this strategy, partly mimicking photoinduced electron transfer processes in the natural photosynthetic reaction center. ${ }^{36,37}$ Cyclodextrins are water-soluble hosts which can assemble molecules of interest in a versatile way. Moreover, in the literature there are examples of the use of cyclodextrins as protection agents against dimerization of the intermediates of the catalytic cycle (i.e. the highly reactive viologen radical cation $\left[\mathbf{M e}-\mathbf{V}-\left.\mathbf{M e}\right|^{\bullet+38-40}\right.$ ) and against the chemical reduction of $[\mathbf{M e}-\mathbf{V}-\mathbf{M e}]^{{ }^{+}}{ }^{+}$by the evolving hydrogen. ${ }^{40,41}$ Cyclodextrins have also been used as "molding matrices" 42 or "supports" 43,44 for the Pt colloids, showing a great influence on overall $\mathrm{H}_{2}$ production probably due to the stabilization of the platinum colloid in solution.

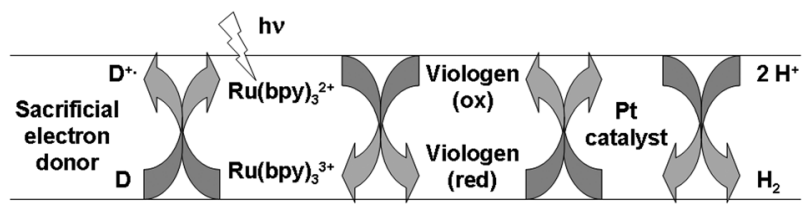

Scheme 1 Representation of a system for hydrogen evolution based on colloidal platinum as catalyst, viologen as electron relay and $\mathrm{Ru}(\mathrm{bpy})_{3}{ }^{2+}$ as sensitizing dye.

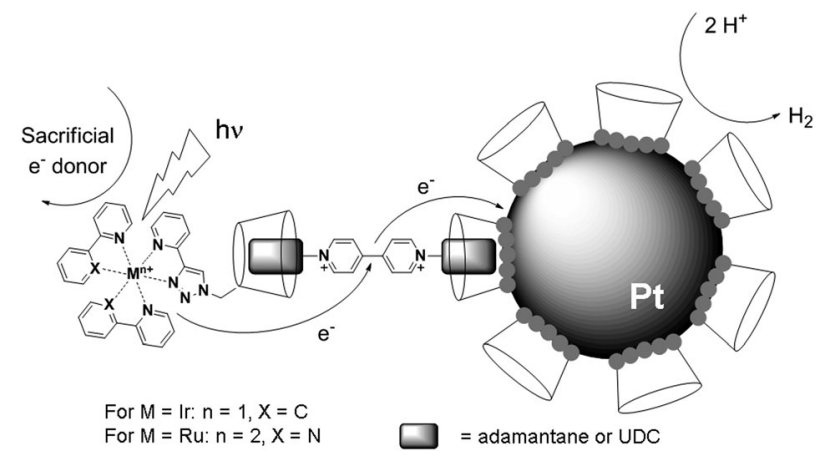

Scheme 2 Schematic representation of the self-assembled three component catalytic system for a more efficient photo-induced electron transfer towards the platinum particle. The Pt nanoparticle is schematically represented as a grey-white sphere, the sulfur atoms of the cyclodextrin in grey, the cyclodextrin as a bucket.

The typical total efficiencies of similar systems as reported in the literature are around or below $0.1 \%$, hydrogen evolution rates range from $\sim 1$ to $9 \mathrm{~mL} \mathrm{~h}^{-1}\left(\sim 40\right.$ to $\left.375 \mu \mathrm{mol} \mathrm{h}^{-1}\right)$; typical light sources are $150 \mathrm{~W}$ Xe lamps. As no standard experimental conditions have yet been established in the photocatalytic community, it is difficult to compare the efficiencies of different systems described in the literature.

The modular supramolecular approach presented in Scheme 2 has the great advantage, compared to a covalently linked multicomponent system, that it allows the generation of several functional photo-active systems by self-assembly from a limited number of building blocks. By combining different elements it will be possible to investigate different selfassembled systems and thus to optimize the experimental conditions. Our long-term aim is to establish whether these three component systems are able to generate hydrogen and whether the supramolecular interactions can provide an efficiency higher than that of collision-controlled analogues. We will describe elsewhere systems that feature viologens which are appended with moieties that have a special affinity for $\beta$-cyclodextrin, such as the adamantane and ursodeoxycholic acid (UDC) mentioned in Scheme 2. We present here an assessment of the other individual components, followed by a discussion of the results of the catalytic study of the system with methyl viologen $[\mathbf{M e}-\mathrm{V}-\mathrm{Me}] \mathrm{Cl}_{2}$.

\section{Materials and methods}

\section{Materials}

Chemicals were purchased from Aldrich, Fluka, or Acros, and used as received. $\left[\operatorname{Ir}(\text { ppy })_{2}(\right.$ pytl-Me $\left.)\right] \mathrm{Cl} \quad(\mathbf{I r}-\mathbf{M e}),{ }^{45}$ $\left[\operatorname{Ir}(\text { ppy })_{2}(\right.$ pytl- $\left.\beta C D)\right] C l(I r-C D),\left[\operatorname{Ir}(\text { ppy })_{2}\right.$ (pytl-ada) $] \mathrm{Cl}$ (Ir-ada), and $\left[\mathrm{Ru}(\mathrm{bpy})_{2}\right.$ (pytl- $\left.\left.\beta \mathrm{CD}\right)\right]_{\mathrm{Cl}}$ (Ru-CD) were prepared as described earlier. ${ }^{35} \mathrm{Pt}$ nanoparticles functionalised with perthiolated $\beta$-cyclodextrins were prepared according to the literature, ${ }^{44}$ details of their characterization are given elsewhere. ${ }^{46}$

\section{Hydrogen evolution experiments}

Hydrogen evolution experiments were carried out under constant irradiation. The system was studied in a home-built cell (Fig. 1). In a typical experiment an aqueous solution 


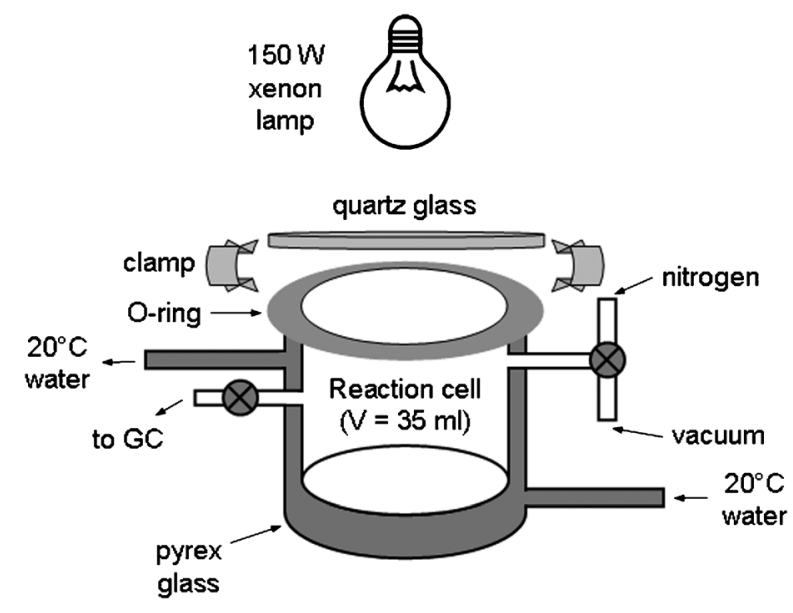

Fig. 1 Schematic representation of the reaction vessel employed in the hydrogen evolution experiments. The cell is covered with a quartz glass lid that is held air-tight with three metal screws. The Xenon lamp $(150 \mathrm{~W})$ continuously irradiated the cell from above. The cell has one inlet for vacuum/nitrogen connected to a Schlenk line and another inlet to take the samples of gas with a microsyringe. The system is kept at a constant temperature.

$(10 \mathrm{~mL})$ was prepared with the sensitizing dye at a concentration in the millimolar range $(0.1 \mathrm{mM})$, combined with a 10 -fold excess of a viologen relay and $1 \mathrm{mg}$ of freshly prepared platinum nanoparticles stabilized with perthiolated- $\beta C D$. To this solution a sacrificial electron donor was added in 100-fold excess with respect to the sensitizing dye. Finally, to assure the presence of enough $\mathrm{H}^{+}$ions, the concentration of $\mathrm{HCl}$ was set to 200 molar equivalents. The solution was then carefully degassed. The total volume of the aqueous solution was always kept at $10 \mathrm{~mL}$ in a cell with capacity for $35 \mathrm{~mL}$. The size of the nanoparticles can greatly affect the efficiency of the hydrogen production, therefore, freshly prepared samples were used, which were stored under an inert atmosphere. To break up possible aggregates, the solutions containing the nanoparticles were sonicated for $30 \mathrm{~min}$ prior to use.

The EDTA/photosensitizer ratio $(100: 1)$ was limited by the solubility of the donor $\left(\mathrm{Na}_{4}\right.$ EDTA); a larger excess would have resulted in a completely turbid solution. At first glance, a higher photosensitizer concentration than $0.1 \mathrm{mM}$ could be expected to give a proportionally higher amount of hydrogen; it was, however, decided to keep the photosensitizer/electron relay ratio at $1: 10$ in order to limit the amount of viologen molecules bound in other assemblies than the effective one shown in Scheme 2, i.e. in the undesirable, non-effective complexes with 2 dye-CDs or $2 \mathrm{Pt}-\mathrm{CDs}$. For the case of methyl viologen, which is exclusively studied here but does not form inclusion complexes (at least not strong ones) with CD, the same ratio was used for comparison. The amount of acid used was chosen to give a low $\mathrm{pH}$ in order to have a high concentration of $\mathrm{H}^{+}$that can be reduced to $\mathrm{H}_{2}$, whilst avoiding too low values which could cause decomposition of metal-CD or the full protonation of $\mathrm{Na}-$ EDTA. The amount of catalyst used was the maximum amount that could be dissolved by 30 min sonication; adding more would have given a very dark suspension which would have resulted in very low yields. The light source was the Xenon lamp HAMAMATSU
L2274 of $150 \mathrm{~W}$. Xenon lamps are popular for demanding absorbance and fluorescence applications as high intensity broadband sources. Because of its sun-like spectrum, the xenon lamp is commonly used for solar simulation. The power supply was a HAMAMATSU C2577 and the lamp housing a HAMAMATSU E2420.

Solutions were monitored for molecular hydrogen evolution by directly measuring the amount of molecular hydrogen contained in the gas phase inside the reaction cell through GC analysis. In order to calculate the moles of hydrogen gas from the chromatographic peak areas, a calibration curve was constructed by preparing different mixtures of $\mathrm{N}_{2}$ and $\mathrm{H}_{2}$ of known ratios and measuring their $\mathrm{H}_{2}$ peak integrals. The gas mixing and injecting processes, as well as the illumination experiment itself, were performed at $T=20{ }^{\circ} \mathrm{C}$ meaning that $1 \mathrm{~mol}$ of gas occupies $24.05 \mathrm{~L}$. It is important to note that all the $\mathrm{H}_{2}$ amounts described hereafter and produced in the photocatalytic cell are determined by analyzing only the gas phase. The $\mathrm{H}_{2}$ which remains dissolved in the solution (at most $8 \mu \mathrm{mol}$ ) - or even entrapped inside bubbles on the solution surface - is not measured. The amount of hydrogen dissolved in solution is in equilibrium and therefore proportional to that in the head space; the amount of $\mathrm{H}_{2}$ dissolved is considered to be representative for that in the gas phase.

\section{Results and discussion}

\section{Photosensitizer and catalyst}

In order to establish whether our approach could lead to the desired goal we need to select the most suitable components and to study their processes separately. It is clear that the chromophoric units must have a number of characteristics for them to be used as sensitizers for our purposes. Among others, high photostability and a long excited state lifetime are a prerequisite. Also, the excited state of the photosensitizer has to be able to transfer an electron to the relay before it returns to the ground state, resulting in a charge-separated state that we can utilize further. Polypyridine complexes are good candidates since they can be excited over a wide range of wavelengths along the visible spectrum, and they can be easily functionalised with cyclodextrins. ${ }^{35}$ Moreover, electron transfer from e.g. a ruthenium polypyridine complex to viologen has been widely documented. ${ }^{30,47,48}$

The complex $\left[\operatorname{Ir}(\text { ppy })_{2}(\text { pytl- } \beta C D)\right]^{+} \quad($ Ir-CD $)$ possesses unique photophysical properties, especially high quantum yield $(0.54)$ and long lifetime $(2.8 \mu \mathrm{s}) .{ }^{35}$ It also shows great water solubility provided by the permethylated cyclodextrin derivative, the cavity of which can also serve as a binding site for modified viologens. In the inclusion complex, the close proximity of the two components will facilitate the electron transfer from the photosensitizer to the mediator and finally to the catalyst. These facts make this complex a perfect candidate as photosensitizer for the production of molecular hydrogen from aqueous acidic solutions. For comparison, the complexes $\left[\operatorname{Ir}(\text { ppy })_{2}(\text { pytl-Me })\right]^{+}(\mathbf{I r}-\mathbf{M e}),\left[\operatorname{Ir}(\text { ppy })_{2}(\text { pytl-ada })\right]^{+}$(Ir-ada), $\left[\mathrm{Ru}(\mathrm{bpy})_{2}(\text { pytl- } \beta \mathrm{CD})\right]^{2+}(\mathbf{R u}-\mathbf{C D})$ and $\left[\mathrm{Ru}(\mathrm{bpy})_{3}\right]^{2+}$ (Ru-bpy) were also examined, as experiments comprising them should give useful information about the behavior of our 

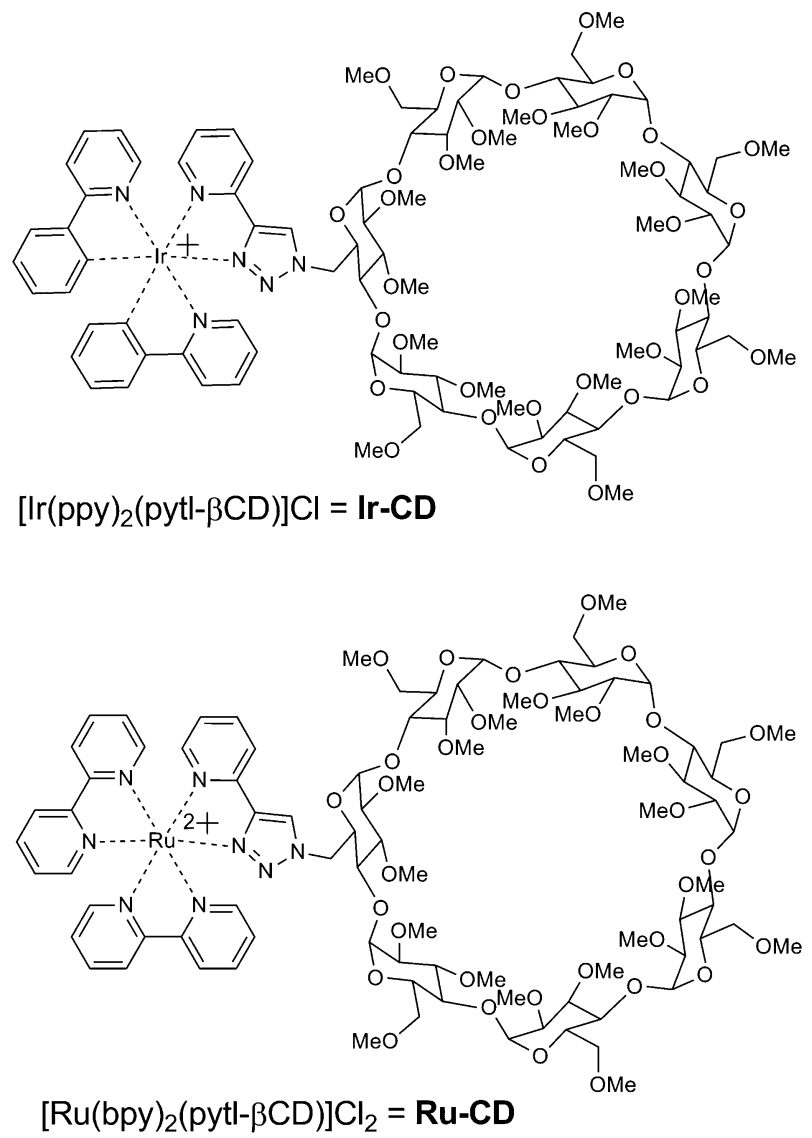

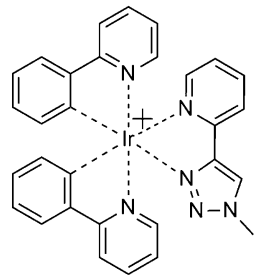
$=\mathrm{Ir}-\mathrm{Me}$

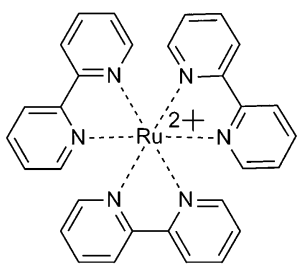

$\left[\mathrm{Ru}(\mathrm{bpy})_{3}\right] \mathrm{Cl}_{2}=\mathbf{R u}$-bpy
$\left[\operatorname{lr}(\mathrm{ppy})_{2}(\mathrm{pytl}-\mathrm{Me})\right] \mathrm{Cl}$

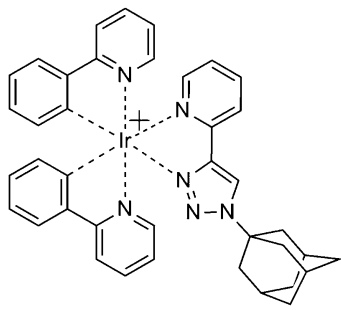

$\left[\operatorname{lr}(\text { ppy })_{2}(\right.$ pytl-ada $\left.)\right] \mathrm{Cl}$ $=$ Ir-ada<smiles></smiles>

$[\mathrm{Me}-\mathrm{V}-\mathrm{Me}] \mathrm{Cl}_{2}$
Scheme 3 Structures of iridium and ruthenium complexes and methyl viologen; counterions $\left(\mathrm{Cl}^{-}\right)$omitted for clarity.

supramolecular photocatalytic system (Scheme 3). The ability of the excited state of both our iridium and ruthenium complexes to transfer an electron to a viologen molecule and to form a long lived charge-separated state was investigated by means of steady-state and time-resolved spectroscopy techniques. ${ }^{35,46}$

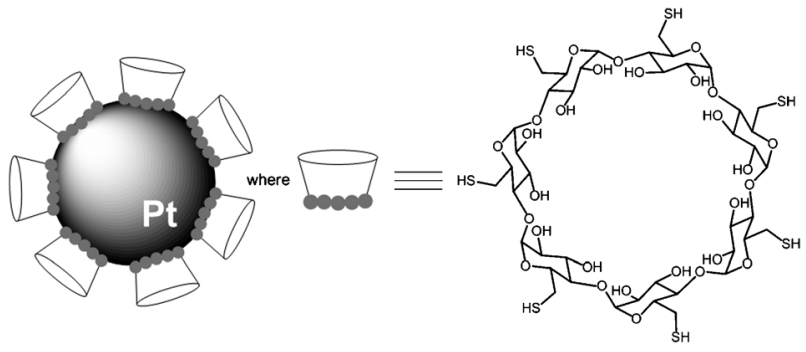

Scheme 4 Schematic representation of the platinum nanoparticles and the stabilizing molecule. The stabilizer is a perthiolated $\beta$-cyclodextrin, the sulfur atoms are represented as grey spheres.

The catalysts we decided to use for our studies were $\mathrm{Pt}$ nanoparticles functionalised with perthiolated $\beta C D$ receptors (Scheme 4). ${ }^{44,46}$ The presence of the cyclodextrins on the nanoparticle surface stabilizes them by preventing aggregation phenomena. ${ }^{49,50}$ At the same time, their surface remains accessible to the substrate and they retain their catalytic activity. ${ }^{51,52}$ The presence of $\mathrm{CD}$ also prevents the adsorption of the larger viologen molecules on the particle surface, avoiding their catalytic irreversible hydrogenation in the presence of molecular hydrogen. ${ }^{53}$ Cyclodextrins also make the nanoparticles soluble in water which is an essential feature for our applications.

The electro-catalytic activity of Pt nanoparticles towards hydrogen reduction is a well-documented process. ${ }^{54}$ The catalyst functions as a condenser/capacitor of negative charge to provide the necessary electrochemical potential and the number of electrons for the reduction of the aqueous protons and serves as a gas evolution site. ${ }^{55}$ This process can be described by the following mechanism when the electron carrier is a reduced viologen: ${ }^{56,57}$

$$
\begin{aligned}
& n[\mathbf{M e}-\mathbf{V}-\mathbf{M e}]^{\bullet+}+\mathrm{Pt} \rightleftharpoons \mathrm{Pt}^{n-}+n[\mathbf{M e}-\mathbf{V}-\mathbf{M e}]^{2+} \\
& \mathrm{Pt}^{n-}+\mathrm{H}^{+} \rightleftharpoons \mathrm{Pt}^{(n-1)-}+\mathrm{H}_{\mathrm{ads}} \\
& 2 \mathrm{H}_{\mathrm{ads}} \rightleftharpoons \mathrm{H}_{2} \uparrow
\end{aligned}
$$

The platinum particles have been investigated by means of cyclic voltammetry which has established that they were active towards the reduction of protons to hydrogen as expected, even at relatively high $\mathrm{pH}(\sim 6)$ values. $^{46}$ The particle size observed for our preparations by TEM $(1.5-2.5 \mathrm{~nm})$ is in the range that is appropriate for application in catalytic reactions $;{ }^{52}$ it allows the diffusion of sufficient $\mathrm{H}^{+}$ions to the surface of the catalyst for the reduction process to $\mathrm{H}_{2}$ to take place. ${ }^{46}$

\section{Viologen and sacrificial electron donor}

Viologen is a very promising electron relay to be used in our systems, with electronic properties that make it suitable to accept one electron from the excited state of iridium and ruthenium metal complexes. We decided to use the $1,1^{\prime}$-disubstituted-4,4'-bipyridine-1, $1^{\prime}$-diium species as chloride salts, where the nitrogens are located in the 'para' position relative to the $\mathrm{C}$ atom where the pyridine rings are connected, thus having the correct geometry to yield linear self-assembled structures. In the present work, we have limited ourselves to 


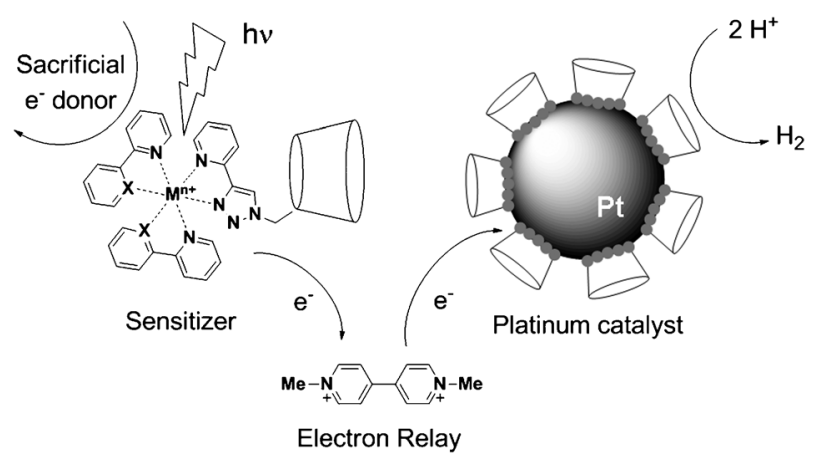

Scheme 5 Chemical structures of the compounds involved in the collision-controlled cyclodextrin-based system for photoinduced hydrogen evolution from water. Ir and $\mathrm{Ru}$ complexes are used as sensitizing dye, methyl viologen as electron relay. The Pt nanoparticle is schematically represented in grey-white, the sulfur atoms of the cyclodextrin in grey. For $\mathrm{M}=\mathrm{Ir}, n=1$ and $\mathrm{X}=\mathrm{C}$; for $\mathrm{M}=\mathrm{Ru}$, $n=2$ and $\mathrm{X}=\mathrm{N}$. The sacrificial donors tested were methanol, EDTA, and TEOA.

the use of the simplest compound of this type, the methyl viologen Me-V-Me (Scheme 3), also known as paraquat, which is a commercially available product. It should be noted that the affinity of Me-V-Me for $\beta \mathrm{CD}$ is too low to give the self-assembled system shown in Scheme 2 for adamantaneand UDC-appended viologens to any significant extent; any $\mathrm{H}_{2}$ evolution detected for the systems described in the present work is controlled by collisions between the components. This system is therefore more appropriately represented as shown in Scheme 5.

To facilitate efficient electron transfer to the Pt center, an electron donor was utilized to re-reduce the photochemically oxidized photosensitizer. ${ }^{10,58}$ As electron donors three candidates were tested: triethanolamine (TEOA) because of its good reducing properties, methanol because of its availability from biomass, and ethylenediaminetetraacetic acid (EDTA) as its sodium salt, a classical example of an electron donor. TEOA was soon discarded because of the formation of insoluble decomposition products that turned the reaction mixtures heavily turbid. Methanol proved to be unsuitable in the experimental conditions used, as it resulted in low hydrogen production yields, probably due to partial evaporation during the degassing procedure; large amounts of methanol can also be expected to decrease the binding abilities of cyclodextrins. Therefore, every experiment described hereafter involves the use of EDTA as a sacrificial donor.

\section{Effect of variation of photosensitizers}

In order to evaluate the effect of the metal center on the efficiency of our systems independently from any other aspects, we investigated the systems Ru-CD/Me-V-Me/Pt- $\beta$ CD/EDTA and Ir-CD/Me-V-Me/Pt- $\beta$ CD/EDTA, which were different only in the nature of the photosensitizers $\mathbf{R u}-\mathbf{C D}$ and $\mathbf{I r - C D}$, containing ruthenium and iridium polypyridine complexes, respectively. The electron mediator used was Me-V-Me in both cases. Illumination of the Ru-CD/Me-V-Me/Pt- $\beta C D /$ EDTA system resulted in a very low yield; only $0.15 \mu$ moles of $\mathrm{H}_{2}$ were produced after the first $15 \mathrm{~min}$ and then the

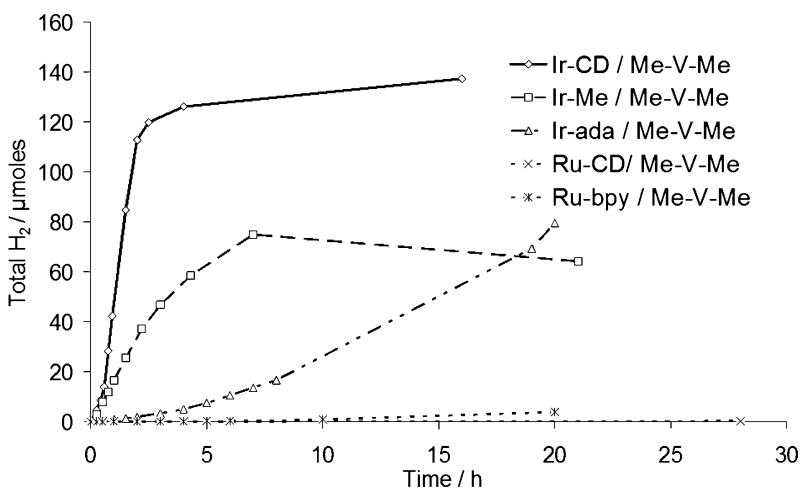

Fig. 2 Plots of molecular hydrogen produced inside the cell headspace as a function of illumination time. The different photosensitizers used $(0.1 \mathrm{mM})$ are shown with different lines. In all cases, the sacrificial donor is EDTA $(10 \mathrm{mM})$, the electron mediator is Me-V-Me $(1 \mathrm{mM})$ and the catalysts are $\beta C D$-modified $\mathrm{Pt}$ nanoparticles $\left(0.1 \mathrm{mg} \mathrm{mL}^{-1}\right)$.

reaction continued at a very low rate, giving $0.36 \mu$ moles of gas after 28 hours (Fig. 2). In the case of Ir-CD/Me-V-Me/ $\mathrm{Pt}-\beta \mathrm{CD} /$ EDTA, where the cyclodextrin-appended ruthenium complex was replaced by the iridium analogue, $4.6 \mu$ moles of $\mathrm{H}_{2}$ were produced during the first 15 minutes (Fig. 2) and the gas evolution was apparent by bubble formation in the solution. The higher efficiency of this system was also shown by the fact that, 3 hours after the illumination started, EDTA was largely consumed as the solution became absolutely transparent (the limited solubility of EDTA, even at low concentrations, was responsible for a turbid solution). As a consequence of the lack of the sacrificial donor, the photosensitizer could not be regenerated anymore and the production of $\mathrm{H}_{2}$ stopped. The total amount of $\mathrm{H}_{2}$ produced was $137 \mu$ moles. In all the experiments we also observed the formation of $\mathrm{CO}_{2}$ (not shown) which originates from the decomposition of EDTA. As expected, the amount of $\mathrm{CO}_{2}$ produced follows the same trend as $\mathrm{H}_{2}$. Taking into consideration that the initial concentration of $\mathrm{HCl}$ was $20 \mathrm{mM}$ - meaning that there are $200 \mu$ moles of $\mathrm{H}^{+}$in the solution which can be reduced to give $100 \mu$ moles of $\mathrm{H}_{2}$ - it is likely that part of the $\mathrm{H}_{2}$ produced originates from the reduction of protons coming either from water or EDTA. In the latter case they are produced during the irreversible decomposition of the oxidized EDTA which comprises the hydrolysis of unstable intermediates. ${ }^{4}$ The substitution of ruthenium with iridium as a light harvesting unit increased the efficiency of the system by approximately 30 times in the initial phase; after 3 hours of illumination the iridium system could produce no more hydrogen because the 100 equivalents of the sacrificial donor were consumed. This remarkable difference in the efficiency of the photocatalytic production of $\mathrm{H}_{2}$ underlines the crucial importance of choosing a very efficient sensitizer, characterized by a high extinction coefficient, to supply a large amount of electrons to the metallic catalyst.

As established earlier ${ }^{35}$ and mentioned above, $\beta$-cyclodextrin can also act as a second-sphere ligand with respect to the metal complex, enhancing, in the case of the iridium species, the excited state quantum yield and lifetime. To investigate the effect of this interaction on the $\mathrm{H}_{2}$ production efficiency, we 
Table 1 Total amount of hydrogen produced by using different photosensitizers

\begin{tabular}{llll}
\hline Photosensitizer & Electron relay & $\begin{array}{l}\text { Time at maximum } \\
\text { concentration } \mathrm{H}_{2} / \mathrm{h}\end{array}$ & $\begin{array}{l}\mathrm{H}_{2} \text { produced/ } \\
\mu \mathrm{mol}\end{array}$ \\
\hline Ir-CD & Me-V-Me & 16 & 137 \\
Ir-Me & & 7 & 75 \\
Ir-ada & & 20 (continuing) & 80 \\
Ru-CD & & 28 (continuing) & 0.4 \\
Ru-bpy & & 20 (con \\
\hline
\end{tabular}

replaced the $\beta C D$ moiety on the iridium complex with a methyl group and used this complex in a similar experiment. The new photosensitizer Ir-Me lacks the inclusion properties of Ir-CD and is characterized by a lower quantum yield (0.35) and shorter lifetime $(2.1 \mu \mathrm{s})$. Interestingly, in the system Ir-Me/ Me-V-Me/Pt- $\beta C D / E D T A$, after $15 \mathrm{~min}$ of irradiation, only $2.8 \mu$ moles of $\mathrm{H}_{2}$ were produced and when the maximum amount of $\mathrm{H}_{2}$ was reached - after 7 hours - $75 \mu$ moles were present in the cell (Fig. 2). The efficiency of the system containing Ir-CD is approximately double that of the system with Ir-Me (Table 1). If we consider that Me-V-Me is not capable of supramolecular interactions with the cyclodextrin cavity, as it does not bear any hydrophobic groups, it is clear that the efficiency of the system is proportional to the quantum yield of the sensitizing dye $\left(\Phi_{\mathbf{I r}-\mathbf{C D}}=0.54, \Phi_{\mathbf{I r - M e}}=0.35\right) .{ }^{35}$ Some other observations can be made. In the Ir-Me experiment (a) the reaction was finished before EDTA was totally consumed and (b) a plateau was reached after 7 hours, compared to 3 hours in the Ir-CD experiment. These facts indicate that the limiting factor in the case of Ir-CD was the initial concentration of the sacrificial donor, whereas in the second experiment the termination of the reaction should be attributed to other causes, possibly the lower turnover number of Ir-Me, due to fewer regeneration cycles.

Another variation of the photosensitizer was Ir-ada which bears an adamantyl group on the pytl ligand and displays an even lower quantum yield and shorter lifetime $(\Phi=0.23$, $\tau=1 \mu \mathrm{s}) .{ }^{35}$ After $15 \mathrm{~min}$ of illumination, the system Ir-ada/ Me-V-Me/Pt- $\beta C D / E D T A$ produced only $0.2 \mu$ moles of hydrogen gas (Fig. 2). The amount of gas kept increasing almost linearly with time and when the experiment was stopped - after 20 hours - $80 \mu$ moles were present in the cell (Table 1). Due to the low reaction rate, we could not determine the maximum amount of hydrogen that could be produced by this system. However, we could estimate that when the photosensitizer is Ir-ada, the resulting system is approximately two times less efficient than the case of Ir-CD. The different kinetic behavior displayed by this system (Fig. 2) might be explained by considering the amphiphilic nature of the photosensitizer. Ir-ada, as we observed by NMR spectroscopy, forms aggregates in water even at low concentrations; this could interfere with the catalytic process by limiting the directional flow of electrons towards the catalytic center. No further investigation was carried out in this direction.

On the basis of the data collected in these studies, we concluded that the efficiency of our systems is directly related to the emission quantum yield of the photosensitizer. The sensitizing dye should be chosen taking into account all the factors affecting its photophysical properties (e.g. formation of inclusion complexes, hydrophobic interactions) as such factors will also have a direct impact on the efficiency of the hydrogen evolution system. The most efficient system was found to be $\mathrm{Ir}-\mathrm{CD} / \mathrm{Me}-\mathrm{V}-\mathrm{Me} / \mathrm{Pt}-\beta \mathrm{CD} / \mathrm{EDTA}$ where the metal center is protected by the cyclodextrin from the quenching of the luminescence. At this time, the higher amount of hydrogen produced is only due to the improved photophysical properties of the sensitizer, as no interactions with $\beta C D$ on either side of methyl viologen are expected.

In order to compare our supramolecular systems with others already reported in the literature, we investigated Ru-bpy/ Me-V-Me/Pt/EDTA, one of the first systems used for photocatalytic production of $\mathrm{H}_{2}$ from water. ${ }^{26,43}$ We carried out some experiments where the efficiency of the latter was evaluated under our working conditions. Surprisingly, during the first hour of illumination, no gas evolution was observed and after 3 hours the amount of $\mathrm{H}_{2}$ produced was only $0.2 \mu$ moles. The reaction rate did not increase until approximately 8 hours after illumination started (Fig. 2). The reaction kept going on even after 20 hours and the final amount of $\mathrm{H}_{2}$ sampled at this time was $3.9 \mu$ moles. Under the conditions used in our experiments, the three iridium complexes Ir-CD, Ir-ada, and Ir-Me, of which Ir-Me is the one most directly comparable to Ru-bpy, are much better antenna molecules than Ru-bpy for $\mathrm{H}_{2}$ production from acidic aqueous solutions. In terms of final gas amount ratios, this is translated as $\mathbf{I r - C D}$, Ir-Me, and Ir-ada being approximately 35,20 and 21 times, respectively, more efficient than Ru-bpy (Table 1).

\section{Conclusions}

Various light-driven catalytic systems for the reduction of $\mathrm{H}^{+}$, comprising of an Ir-complex photosensitizer, a viologen-based electron relay, cyclodextrin-modified platinum nanoparticles as the catalyst, and a sacrificial donor, are capable of producing molecular hydrogen. The yields measured are at least an order of magnitude higher than the known Ru-bpy/Me-V-Me/Pt/ EDTA system. The most efficient combination was found to be Ir-CD/Me-V-Me/Pt- $\beta \mathrm{CD} /$ EDTA, producing almost $32 \mu$ moles $(\sim 0.75 \mathrm{~mL})$ of $\mathrm{H}_{2}$ per hour from a $10 \mathrm{~mL}$ solution (actual yields are higher since part of the gas remains in solution). We investigated the effect of the photosensitizer on the efficiency of our systems and it was found that the total amount of hydrogen produced was directly proportional to the emission quantum yield of the photosensitizer, implying that a long-lived excited state is beneficial. An obvious improvement to take advantage of the efficiency of the combination of a CD-appended Ir-based photosensitizer and $\mathrm{CD}$-coated $\mathrm{Pt}$ nanoparticles would be to use viologens that are appended with moieties that are good guests for cyclodextrins such as adamantane and UDC, which would lead to catalytic systems that self-assemble by host-guest interactions; work along these lines is in progress.

\section{Acknowledgements}

The authors thank the European Union for support through the Marie Curie Research and Training Network UNI-NANOCUPS (MRTN-CT-2003-504233). M. F. acknowledges 
University 'La Sapienza' of Rome for a scholarship. R. J. M. N. acknowledges the Royal Netherlands Academy for Arts and Sciences (KNAW) for financial support.

\section{References}

1 T. Nussbaumer, Energy Fuels, 2003, 17, 1510-1521.

2 E. Amouyal, Sol. Energy Mater. Sol. Cells, 1995, 38, 249-276.

3 W. Lubitz and W. Tumas, Chem. Rev., 2007, 107, 3900-3903.

4 A. J. Esswein and D. G. Nocera, Chem. Rev., 2007, 107, 4022-4047.

5 N. W. Ockwig and T. M. Nenoff, Chem. Rev., 2007, 107, 4078-4110.

6 V. V. Struzhkin, B. Militzer, W. L. Mao, H. K. Mao and R. J. Hemley, Chem. Rev., 2007, 107, 4133-4151.

7 R. Borup, J. Meyers, B. Pivovar, Y. S. Kim, R. Mukundan, N. Garland, D. Myers, M. Wilson, F. Garzon, D. Wood, P. Zelenay, K. More, K. Stroh, T. Zawodzinski, J. Boncella, J. E. McGrath, M. Inaba, K. Miyatake, M. Hori, K. Ota, Z. Ogumi, S. Miyata, A. Nishikata, Z. Siroma, Y. Uchimoto, K. Yasuda, K. I. Kimijima and N. Iwashita, Chem. Rev., 2007, 107, 3904-3951.

8 J. Kiwi and M. Grätzel, Nature, 1979, 281, 657-658.

9 M. Kirch, J. M. Lehn and J. P. Sauvage, Helv. Chim. Acta, 1979, 62, 1345-1384.

10 K. Kalyanasundaram, J. Kiwi and M. Grätzel, Helv. Chim. Acta, 1978, 61, 2720-2730.

11 P. Ritterskamp, A. Kuklya, M. A. Wüstkamp, K. Kerpen, C. Weidenthaler and M. Demuth, Angew. Chem., Int. Ed., 2007, 46, 7770-7774.

12 D. W. Hwang, H. G. Kim, J. S. Lee, J. Kim, W. Li and S. Hyuk Oh, J. Phys. Chem. B, 2005, 109, 2093-2102.

13 W. Shangguan and A. Yoshida, J. Phys. Chem. B, 2002, 106, 12227-12230.

14 I. Tsuij, H. Kato and A. Kudo, Chem. Mater., 2006, 18, 1969-1975.

15 M. Anpo, Catal. Surv. Jpn., 1997, 1, 169-179.

16 A. Kudo, Int. J. Hydrogen Energy, 2006, 31, 197-202.

17 K. Maeda, K. Teramura, D. Lu, T. Takata, N. Saito, Y. Inoue and K. Domen, Nature, 2006, 440, 295.

18 J. R. Darwent, P. Douglas, A. Harriman, G. Porter and M. C. Richoux, Coord. Chem. Rev., 1982, 44, 83-126.

19 I. Okura, Coord. Chem. Rev., 1985, 68, 53-99.

20 Y. Amao and I. Okura, J. Mol. Catal. B: Enzym., 2002, 17, 9-21.

21 J. Handman, A. Harriman and G. Porter, Nature, 1984, 307, 534-535.

22 I. Okura and H. Hosono, J. Phys. Chem., 1992, 96, 4466-4469.

23 D. L. Jiang, C. K. Choi, K. Honda, W. S. Li, T. Yuzawa and T. Aida, J. Am. Chem. Soc., 2004, 126, 12084-12089.

24 Y. Astuti, E. Palomares, S. A. Haque and J. R. Durrant, J. Am. Chem. Soc., 2005, 127, 15120-15126.

25 N. Himeshima and Y. Amao, Energy Fuels, 2003, 17, 1641-1644.

26 M. Grätzel, Acc. Chem. Res., 1981, 14, 376-384.

27 N. Serpone, E. Pelizzetti and M. Grätzel, Coord. Chem. Rev., 1985, 64, 225-245.

28 C. G. Garcia, J. F. de Lima and N. Y. Murakami Iha, Coord. Chem. Rev., 2000, 196, 219-247.

29 G. M. Brown, S. F. Chan, C. Creutz, H. A. Schwarz and N. Sutin, J. Am. Chem. Soc., 1979, 101, 7638-7640.

30 E. H. Yonemoto, G. B. Saupe, R. H. Schmehl, S. M. Hubig, R. L. Riley, B. L. Iverson and T. E. Mallouk, J. Am. Chem. Soc., 1994, 116, 4786-4795.
31 A. Auffrant, A. Barbieri, F. Barigelletti, J. Lacour, P. Mobian, J. P. Collin, J. P. Sauvage and B. Ventura, Inorg. Chem., 2007, 46, 6911-6919.

32 L. L. Tinker, N. D. McDaniel, P. N. Curtin, C. K. Smith, M. J. Ireland and S. Bernhard, Chem.-Eur. J., 2007, 13, $8726-8732$.

33 J. I. Goldsmith, W. R. Hudson, M. S. Lowry, T. H. Anderson and S. Bernhard, J. Am. Chem. Soc., 2005, 127, 7502-7510.

34 D. R. Rosseinsky and P. M. S. Monk, J. Chem. Soc., Faraday Trans., 1990, 86, 3597-3601.

35 M. Felici, P. Contreras-Carballada, Y. Vida, J. M. M. Smits, R. J. M. Nolte, L. De Cola, R. M. Williams and M. C. Feiters, Chem.-Eur. J., 2009, 15, 13124-13134.

36 N. Krauss, W. Hinrichs, I. Witt, P. Fromme, W. Pritzkow, Z. Dauter, C. Betzel, K. S. Wilson, H. T. Witt and W. Saenger, Nature, 1993, 361, 326-330.

37 W. Kuhlbrandt, D. N. Wang and Y. Fujiyoshi, Nature, 1994, 367, 614-621.

38 J. W. Park, N. H. Choi and J. A. Kim, J. Phys. Chem., 1996, 100, 769-774.

39 A. Diaz, P. A. Quintela, J. M. Schuette and A. E. Kaifer, J. Phys. Chem., 1988, 92, 3537-3542.

40 Y. Okuno, Y. Chiba and O. Yonemitsu, J. Chem. Soc., Chem. Commun., 1984, 1638-1639.

41 O. Johansen, A. Launikonis, J. W. Loder, A. W. H. Mau, W. H. F. Sasse, J. D. Swift and D. Wells, Aust. J. Chem., 1981, 34, 2347-2354.

42 N. P. Luneva, V. Y. Shafirovich and A. E. Shilov, Kinet. Katal., 1988, 30, 250-251.

43 Y. Okuno, Y. Chiba and O. Yonemitsu, Chem. Lett., 1983, 893-896.

44 J. Alvarez, J. Liu, E. Roman and A. E. Kaifer, Chem. Commun., $2000,1151-1152$.

45 S. Zanarini, M. Felici, G. Valenti, M. Marcaccio, L. Prodi, S. Bonacchi, P. Contreras-Carballada, R. M. Williams, M. C. Feiters, R. J. M. Nolte, L. De Cola and F. Paolucci, Chem.-Eur. J., DOI: 10.1002/chem.201002956.

46 M. Peruffo, P. Contreras-Carballada, P. Bertoncello, R. M. Williams, L. De Cola and P. R. Unwin, Electrochem. Commun., 2009, 11, 1885-1887.

47 H. F. M. Nelissen, M. Kercher, L. De Cola, M. C. Feiters and R. J. M. Nolte, Chem.-Eur. J., 2002, 8, 5407-5414.

48 T. Hiraishi, T. Kamachi and I. Okura, J. Mol. Catal. A: Chem., $2000,151,7-15$.

49 A. C. Templeton, W. P. Wuelfing and R. W. Murray, Acc. Chem. Res., 2000, 33, 27-36.

50 Y. Liu, K. B. Male, P. Bouvrette and J. H. T. Luong, Chem. Mater., 2003, 15, 4172-4180.

51 J. Liu, J. Alvarez, W. Ong, E. Roman and A. E. Kaifer, Langmuir, 2001, 17, 6762-6764.

52 L. Strimbu, J. Liu and A. E. Kaifer, Langmuir, 2003, 19, 483-485.

53 V. E. Maier and V. Y. Shafirovich, Kinet. Katal., 1988, 29, 417-420.

54 S. Trasatti and O. A. Petrii, J. Electroanal. Chem., 1992, 327, 353-376.

55 A. J. Bard and M. A. Fox, Acc. Chem. Res., 1995, 28, 141-145.

56 M. S. Matheson, P. C. Lee and D. Meisel, J. Phys. Chem., 1983, 87, 394-399.

57 W. J. Albery, P. N. Bartlett and A. J. McMahon, J. Electroanal. Chem., 1985, 182, 7-23.

58 S. Rau, B. Schäfer, D. Gleich, E. Anders, M. Rudolph, M. Friedrich, H. Görls, W. Henry and J. G. Vos, Angew. Chem., Int. Ed., 2006, 45, 6215-6218. 